\title{
EXPLORATION OF PLANT BIOACTIVE FROM CASSIA FISTULA LEAVES FOR THE TREATMENT OF OVARIAN CANCER: AN INTEGRATIVE APPROACH
}

\author{
KANIKA VERMA, SHANTHI VEERAPPAPILLAI, RAMANATHAN KARUPPASAMY*
}

\author{
Department of Biotechnology, School of Bio Sciences and Technology, VIT University, Vellore - 632 014, Tamil Nadu, India. \\ Email: kramanathan@vit.ac.in
}

Received: 01 June 2016, Revised and Accepted: 08 June 2016

\section{ABSTRACT}

Objective: Paclitaxel is one of the most effective anticancer agents. It is used as a chemotherapy agent for a spectrum of cancer types. However, paclitaxel resistance is one of the foremost problems for chemotherapy. Most importantly, an emergence of paclitaxel resistance due to mutation (F270V) in $\beta$-tubulin has been extremely deliberated in recent years. With the rise of paclitaxel-resistant mutation in $\beta$-tubulin, there is a need to add a novel inhibitor from natural source, as they have less chance of getting resistance additionally less side effects. Keeping this in mind, we have utilized experimental and in silico approaches to isolate the potent inhibitor for $\beta$-tubulin target protein.

Methods: We have extracted phytocompounds from Cassia fistula plant, and the structures were recognized with the help of gas chromatographymass spectrometry technique. Subsequently, oral bioavailability and toxicity analysis were executed for the extracted compounds by employing MOLINSPIRATION and OSIRIS program, respectively. Furthermore, docking analysis was performed using YASARA algorithm. In addition, bioactivity analysis for the screened compounds was performed using prediction of activity spectra for substances program.

Results: The results from our analysis clearly depict that HOP-22(29)-EN-3.BETA.-OL could be a promising inhibitor for the treatment of cancer and provide direction for future research. Further in vitro and in vivo exploration is also required to identify whether HOP-22(29)-EN-3.BETA.-OL have anticancer effect or not.

Conclusion: The combination of computational approach and experimental analysis provides an easy approach to identify novel candidate for the target protein $\beta$-tubulin.

Keywords: Phytochemicals, Gas chromatography mass spectrometry, Bioavailability, Molecular docking, Prediction of activity spectra for substances prediction.

(C) 2016 The Authors. Published by Innovare Academic Sciences Pvt Ltd. This is an open access article under the CC BY license (http://creativecommons org/licenses/by/4. 0/) DOI: http://dx.doi.org/10.22159/ajpcr.2016.v9i5.13187

\section{INTRODUCTION}

About 3\% of cancers among women associate for ovarian cancer, it causes high death rates than any other types of cancer in the reproductive system of female. Ovarian cancers inherent danger to women's health is connected by the bottom line that it is notably very complicated to detect. The major cause of high death rates for the diseases immediately needs to be dealt with through safe and effective new treatments. Ovarian cancer has come out as one of the most widespread malignancy affecting women in India. The chemotherapeutic agents particularly paclitaxel is one of the widely used drugs for the treatment against a variety of tumors including breast, ovarian, lung and head, and neck cancers $[1,2]$. It targets $\beta$-subunit (i.e., $\beta$-tubulin) of microtubules. This $\beta$-subunit makes heterodimer with the $\alpha$-subunit to build microtubules. Paclitaxel binds to the $\beta$-subunit part and makes the microtubule stabilized against depolymerization. This, in turn, leads to the decrease in the dynamic behavior of microtubules and leads to a mitotic arrest in cell cycle and apoptosis process [3]. Even though, paclitaxel is a widely used chemotherapeutic agent, the advancement of resistance has limited its use in clinical trials as other chemotherapeutic drugs [4]. Most importantly, resistance due mutation is the major cause of paclitaxel resistance in the $\beta$-subunit of microtubules. Of note, mutation at position 270 in $\beta$-tubulin (phenylalanine to valine) leads to paclitaxel resistance at higher levels in the patients. Thus, there is a keen interest in the discovery of potent $\beta$-tubulin inhibitors which may help to overcome paclitaxel resistance in the treatment of ovarian cancer. These problems could be addressed definitely by the help of computational approaches. Most importantly, plants as a source of bioactive components with anticancer properties can be served as chemotherapeutic agents for the treatment of cancer. Moreover, $60 \%$ of drugs available in market are derived from plant sources such as paclitaxel $[5,6]$. Keeping this in mind, the present study targets to identify potent inhibitors from the plant Cassia fistula [7-9] to target $\beta$-tubulin for the treatment of ovarian cancer. We hope our study will be valuable in the designing of new anticancer agents for the treatment of ovarian cancer in near future.

\section{METHODS}

Collection of plant leaves

C. fistula plant leaves were collected from the nursery at VIT University, Vellore, Tamil Nadu, India.

\section{Washing, drying and powdering of plant leaves}

The collected leaves were then washed under a running tap to remove any dirt or unwanted substances. The leaves were then dried under a shaded area at room temperature for few days until the moisture was removed. The leaves were then crushed and powdered for use in the extraction process. The powdered leaves were then further filtered using an infuser to obtain a fine powder.

\section{Plant extract preparation}

C. fistula powder obtained was then dissolved in four different solvents: Ethanol (polar), Methanol (polar), diethyl ether (mid-polar), and chloroform (non-polar). The ratio of the extraction solution being one part leaf powder to three parts of the solvent (1:3). The prepared mixture was kept for a period of $72 \mathrm{hrs}$ at a temperature of $60-65^{\circ} \mathrm{C}$ during which it is stirred after every 3 hrs. The extracts obtained from each solvent were filtered using Whatman filter paper. The filtrate obtained was then subjected to a drying process using Petri plates and stored in room temperature for $48 \mathrm{hrs}$ for the complete removal of solvent [10]. 
Further gas chromatography-mass spectrometry (GC-MS) [11] analysis was performed using $0.50 \mu \mathrm{g}$ of dried extract sample.

\section{GC-MS analysis of phytochemical compounds}

GC-MS analysis is the most preferable technique for analyzing the chemical compounds in the plant extract. It helps in the identification [12] of structures. Furthermore, it provides the information like name, molecular weight (MW), and structure of the compounds on interpretation by mass spectrum [13]. $10 \mathrm{mg}$ of the extract is used for the GC-MS analysis. Perkin Elmer GC-MS (Model PerkinElmer Clarus 600, USA) equipped with VF-5 MS fused silica capillary column was employed for the GC-MS analysis of the extracts. GC-MS spectroscopic detection, an electron ionization system with ionization energy of 70 electron volt was used. Mass transfer line and injector temperatures were set at $250^{\circ} \mathrm{C}$. Helium gas was used as a carrier gas at a constant flow rate of $1 \mathrm{~mL}$ per minute [14-16]. The oven temperature was kept at $60^{\circ} \mathrm{C}$ for 2 minutes then increased to $300^{\circ} \mathrm{C}$ for 6 minutes at the rate of $10^{\circ} \mathrm{C}$ per minute. The same samples were injected in split mode as 10:1 [10].

\section{Identification of phytocompounds}

National Institute Standard and Technology (NIST) was used to interpret the results of mass spectrum. It is a database which consists of more than 62,000 patterns. The spectrum of the unidentified substance was compared with the known fragments stored in the library of NIST The retention time, MW, name, structure, and concentration (\%) of the substance analyzed were taken into account [17]. Of note, the results will be obtained in the form of chromatogram which contains numerous peaks which have a repertoire of phytocompounds.

\section{Data set for in silico analysis}

The $\beta$-tubulin structure used in our analysis was obtained from the Protein Data Bank (PDB). 1TVK [18] is the PDB code which corresponds to $\beta$-tubulin. The mutant (F270V) structure was generated using SwissPDB viewer [19]. Paclitaxel was used as reference drug for our study. The structures of the phytocompounds were obtained from the result of GCMS, Wiley 9 library analysis. For instance, a total of 29 compounds were examined for their inhibiting activity against $\beta$-tubulin. The SMILES notations for these compounds were retrieved from PubChem (NCBI) [20] and submitted to CORINA for deducing the 3D structure of compounds [21].

\section{Oral bioavailability and toxicity analysis}

Bioavailability and permeability are two important molecular properties. They are always associated with various molecular descriptors such as $\log \mathrm{P}$ (partition coefficient), MW, hydrogen bond acceptor, and donor counts are also important in a molecule [22]. These all molecular properties were used in framing "Lipinki's Rule of Five (LROF)" [23]. According to this the molecules with good membrane permeability have MW $\leq 500$, calculated octanol-water partition coefficient, $\log \mathrm{P} \leq 5$, hydrogen bond donors $\leq 5$, acceptors $\leq 10$, and van der Waals bumps polar surface area $<120 \AA 2$ [24]. As a result, LROF was employed to check the bioavailability (ADME) of the compounds. In the study, molecular properties of all the compounds were calculated using MOLINSPIRATION program [25]. In addition to this the screening was also carried out by restricting the number of violations to a maximum of two. Subsequently, toxicity analysis was done to discover an effective drug, high-quality compounds which may need to be more drug-like than generally acknowledged. And to attain this, it is very important to eliminate the compounds with poor pharmacokinetics and toxicity in early stages of drug discovery. These biochemical properties were, therefore, estimated utilizing OSIRIS program [26] for the filtered set of compounds. The OSIRIS program calculates mutagenicity, tumorogenicity, irritating effects, and reproductive effects which may be used to evaluate the potent inhibitor compound and to meet the requirements for a drug. Of note, the physiochemical and pharmacokinetics properties may be used to evaluate the compounds potential to qualify as a drug candidate. Thus, the compounds fulfilling this criterion were further subjected to docking studies.
Molecular docking analysis of phytocompounds

Molecular Docking study was performed to understand the binding affinity of compounds with the native and mutant (F270V) type $\beta$-tubulin protein. AutodockVina [27] algorithm incorporated in YASARA software package [28] was used to execute molecular docking studies. The difference between the sum of potential and solvation energies of the separated compounds and the sum of potential and solvation energies of the complex in the YAMBER3 force field was utilized to calculate the energy. For instance, more positive energy value implies higher binding affinity and less positive energy means lower binding affinity. The best 10 clusters score were generated for both the native and mutant type complexes. The best confirmation of native and mutant $\beta$-tubulin complex was selected among 10 clusters for further analysis. Moreover, anticancer activity analysis was done for the compounds by employing CDRUG program.

\section{Anti-cancer activity analysis of the compounds: CDRUG}

Screening of millions and millions of compounds for anticancer activity is a very tough, expensive and time taking task. A fast and user-friendly server known as CDRUG is described for the prediction of anticancer efficiency of various chemicals. In this study, we have employed CDRUG to cross-check whether the extracted bioactives from the plant poses anti-cancerous property or not [29] CDRUG employs a novel molecular description technique (relative frequency-weighted fingerprint) to execute the fingerprints of the compound. Of note, the similarity between the query and the active compound was measured which in turn results in the form of hybrid score. Finally, it estimates $\mathrm{p}$ value (confidence level) which helps in predicting whether the query compound(s) have or do not have anti-cancerous activity [29]. Therefore, $p$ value of compounds which shows higher binding energies was calculated by employing CDRUG. The $p$ value cutoff $(p<0.01)$ and $\mathrm{H}$-score value $>1.0$ was taken into consideration [30] for the analysis. Moreover, the output page of the CDRUG shows the result based on color range, i.e., highly possible, possible and less possible results are colored by green, black and gray, respectively. The compounds falling under these criteria may have anticancer activity. Further, the compounds were evaluated for the biological activity using PASS prediction

\section{Prediction of activity spectra for substances (PASS)}

Prediction of anticancer activity of the compounds extracted from C. fistula was done with the help of PASS [31] program. It is a computer-based program used for the prediction of different types of pharmacological activities of the substances [31] including phytocompounds. The prediction by PASS is based on structural activity relationship analysis of the training set containing more than 205,000 compounds exhibiting more than 3750 kinds of biological activities. The predicted activity spectrum of a compound is estimated as probable activity $(\mathrm{Pa})$ and probable inactivity [32]. If $\mathrm{Pa}$ is more than 0.7 then the substance is very likely to exhibit the activity in experiment and the substance may be known pharmaceutical agent, if Pa is less than 0.5 , then the substance is very unlikely to exhibit the activity in experiment, but the presence will be confirmed by the experiment and if $\mathrm{Pa}$ is less than 0.5 and more than 0.7 , the substance is likely to exhibit the activity in experiment and the substance may or may not have biological activity [31,32].

\section{RESULTS AND DISCUSSIONS}

\section{GC-MS analysis}

The GC-MS analysis of phytocompounds in the ethanol, methanol, diethyl ether, and chloroform leaf extract of $C$. fistula explored the presence of various bioactive components. The identification of the phytocompounds was confirmed based on the molecular formula and its structure. The results are presented in Table 1 . The results of GC-MS show that $C$. fistula contains 29 bioactive compounds which are extracted using different solvent in our study. Further, these 29 compounds were considered for ADME and toxicity analysis. 
Table 1: List of phytocompounds extracted from the leaves of Cassia fistula

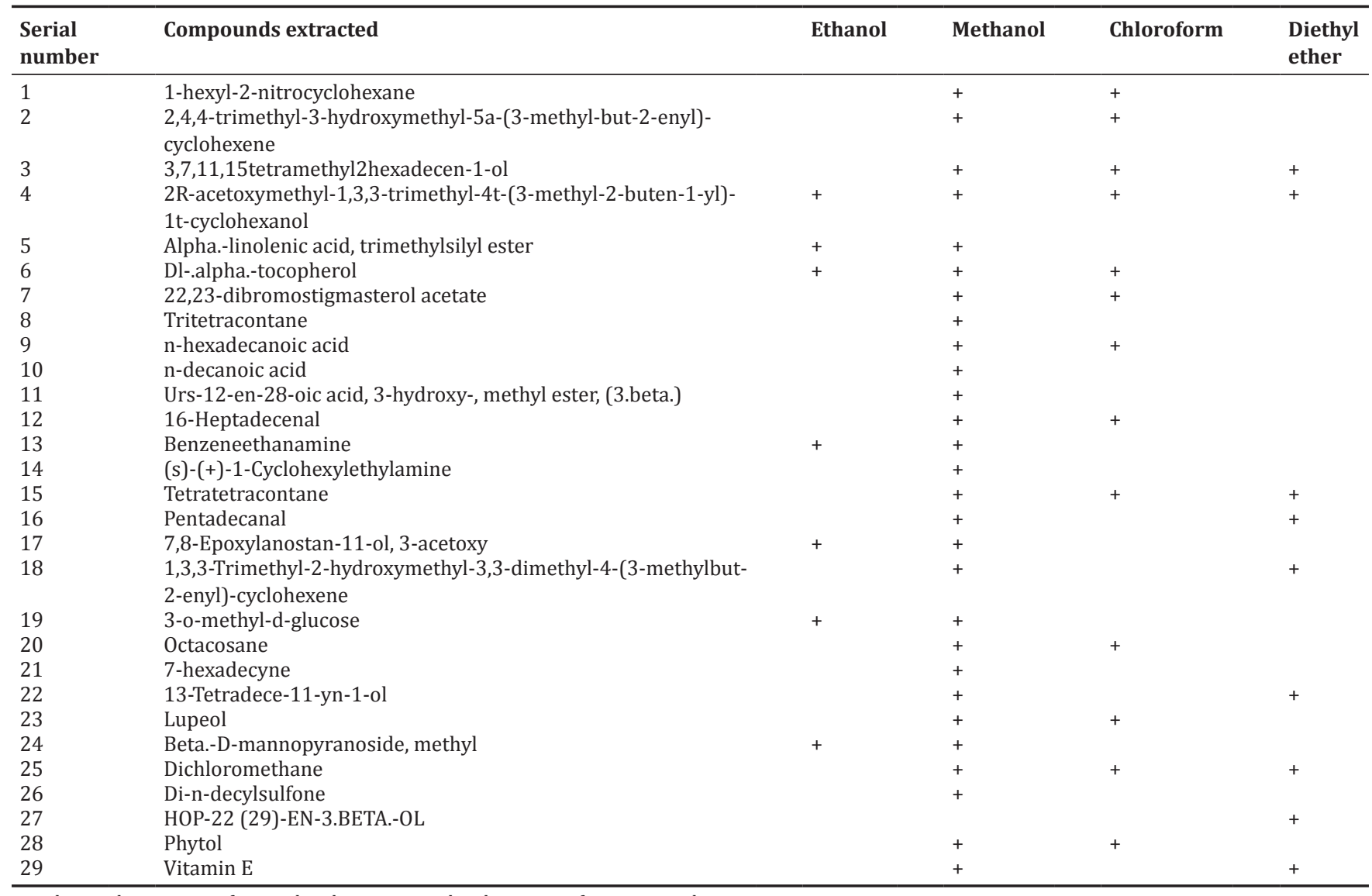

+ indicates the presence of particular phytocompound in the extract of respective solvent

\section{Bioavailability and toxicity assessment}

A total of 29 bioactives extracted from C. fistula alongside paclitaxel as reference drug were considered in our study. The preliminary screening of the compounds was accomplished on the basis of two descriptors such as pharmacokinetics and toxicity. The data corresponds to the paclitaxel were set as the threshold value for screening the lead molecules in all the categories. At first, the pharmacokinetics property of the leads was examined using LROF with the help of molinspiration program. The output results of molinspiration program were presented in Table 2. It is clear from the Table 2 that paclitaxel showed 2 violations to the LROF. Further, the numbers of violations of the lead compounds resulted from the molinspiration program were mapped with the number of violations of paclitaxel for the criterion of screening. For instance, the results from our Table 2 indicate that 5 compounds showed 2 violations in the bioavailability analysis and another 14 compounds showed 1 violation to the LROF. Of note, 11 more compounds from our data set showed zero violation to the LROF. Accordingly, 30 compounds from our dataset were chosen for further analysis. Subsequently, the toxicity of the screened compounds was examined using OSIRIS program. The results are shown in Table 3. The results, from our study, indicate that 19 compounds from our dataset show no mutagenicity, no tumorigenicity, no reproductive effect, and no irritant properties in our data set of 30 molecules. However, 11 compounds from the list of 30 compounds show toxicity risk when run through the OSIRIS program. Therefore, molecular docking analysis was initiated for the compounds.

\section{Molecular docking studies}

Docking studies were executed to understand the binding efficiency of the compounds derived from the plant $C$. fistula with the protein $\beta$-tubulin. We have considered 29 compounds and paclitaxel for the docking study. The docked ligand complexes were analyzed based on binding energy. The results indicate that compound HOP22(29)-EN-3.BETA.-OL has better binding energy both with native and mutant type $\beta$-tubulin in compare to other compounds and also in compare to the paclitaxel. The results are shown in Table 4. Of the 29 compounds, 3 compounds (Urs-12-En-28-Oic Acid, 3-Hydroxy-, Methyl Ester, (3.Beta.), HOP-22(29)-EN-3.BETA.-OL, and Lupeol show the best binding energy over paclitaxel. The binding free energies of the native and mutant types of $\beta$-tubulin paclitaxel complex were 8.75 and $7.51 \mathrm{kcal} / \mathrm{mol}$, respectively; on the other hand, HOP-22(29)EN-3.BETA.-OL shows the binding energy of 9.22 and $9.44 \mathrm{kcal} / \mathrm{mol}$. The binding energy indicates that the efficiency of HOP-22(29)-EN-3. BETA.-OL is competent in compare to paclitaxel with mutant protein. Thus, HOP-22(29)-EN-3.BETA.-OL can be a potent molecule to overwhelm with drug resistance problem in the treatment of ovarian cancer. Subsequently, we have examined compounds for analyzing the anticancer activity by employing CDRUG server.

\section{Inferring anticancer potential of the extracted bioactives}

The anti-cancer activity of the compounds with higher binding energy was evaluated using CDRUG. To infer the compound to be a potential candidate for the treatment of ovarian cancer, we have first filtered the compounds based on its binding affinity with the target protein $\beta$-tubulin and we found 3 (HOP-22(29)-EN-3.BETA.-OL; Urs-12-En-28Oic Acid, 3-Hydroxy-, Methyl Ester, (3.Beta.) and Lupeol) compounds showing higher affinity to bind with the target protein. Then, we predicted the anticancer activity of these compounds alongside paclitaxel. The results are displayed in Fig. 1. The results clearly depict that the compound HOP-22(29)-EN-3.BETA.-OL have anticancer activity and also higher binding energy in compare to other compounds and paclitaxel. The compounds are found to be in comparable zone on the basis of $\mathrm{H}$-score (H-score not $>1$ ) p value and Color code. Therefore, we have examined the compound for its biological activity to pick up the 
Table 2: Oral bioavailability analysis of the phytocompounds using molinspiration program

\begin{tabular}{|c|c|c|c|c|c|c|c|c|c|c|}
\hline $\begin{array}{l}\text { Serial } \\
\text { number }\end{array}$ & Compounds name & miLogP & TPSA & NAtoms & MW & nON & nOHNH & Nviolations & Nrotb & volume \\
\hline 1 & 1-hexyl-2-nitrocyclohexane & 4.82 & 45.824 & 15 & 213.321 & 3 & 0 & 0 & 6 & 226.56 \\
\hline 2 & $\begin{array}{l}\text { 2,4,4-trimethyl-3-hydroxymethyl- } \\
\text { 5a-(3-methyl-but-2-enyl)- } \\
\text { cyclohexene }\end{array}$ & 4.725 & 20.228 & 16 & 222.372 & 1 & 1 & 0 & 3 & 258.014 \\
\hline 3 & $\begin{array}{l}\text { 2R-acetoxymethyl-1,3,3- } \\
\text { trimethyl-4t-(3-methyl-2-buten- } \\
\text { 1-yl)-1t-cyclohexanol }\end{array}$ & 4.434 & 46.533 & 20 & 282.424 & 3 & 1 & 0 & 5 & 298.432 \\
\hline 4 & $\begin{array}{l}\text { Alpha.-linolenic acid, } \\
\text { trimethylsilyl ester }\end{array}$ & 8.71 & 26.305 & 24 & 350.619 & 2 & 0 & 1 & 15 & 386.664 \\
\hline 5 & Dl-.alpha.-tocopherol & 9.043 & 29.462 & 31 & 430 & 2 & 1 & 1 & 12 & 474.499 \\
\hline 6 & $\begin{array}{l}\text { 22,23-dibromostigmasterol } \\
\text { acetate }\end{array}$ & 9.244 & 26.305 & 35 & 614.547 & 2 & 0 & 2 & 8 & 528.851 \\
\hline 7 & Tritetracontane & 10.731 & 0 & 43 & 605.177 & 0 & 0 & 2 & 40 & 734.631 \\
\hline 8 & n-hexadecanoic acid & 7.059 & 37.299 & 18 & 256.43 & 2 & 1 & 1 & 14 & 291.422 \\
\hline 9 & n-decanoic acid & 4.027 & 37.299 & 12 & 172.268 & 2 & 1 & 0 & 8 & 190.612 \\
\hline 11 & 16-heptadecanal & 6.034 & 43.376 & 21 & 298.467 & 3 & 0 & 1 & 16 & 327.96 \\
\hline 12 & Benzeneethanamine & 3.875 & 3.238 & 18 & 239.362 & 1 & 0 & 0 & 5 & 251.789 \\
\hline 13 & $(\mathrm{~s})-(+)-1$-cyclohexylethylamine & 1.807 & 26.023 & 9 & 127.231 & 1 & 2 & 0 & 1 & 147.307 \\
\hline 14 & Tetratetracontane & 10.763 & 0 & 44 & 619.204 & 0 & 0 & 2 & 41 & 751.433 \\
\hline 15 & Pentadecanal & 7.128 & 17.071 & 16 & 226.404 & 1 & 0 & 1 & 13 & 266.603 \\
\hline 16 & Phytol & 6.761 & 20.228 & 21 & 296.539 & 1 & 1 & 1 & 13 & 349.376 \\
\hline 17 & $\begin{array}{l}\text { 7,8-epoxylanostan-11-ol, } \\
\text { 3-acetoxy }\end{array}$ & 7.974 & 59.061 & 36 & 502.78 & 4 & 1 & 2 & 7 & 520.801 \\
\hline 18 & $\begin{array}{l}\text { 1,3,3-trimethyl-2-hydroxymethyl- } \\
\text { 3,3-dimethyl-4-(3-methylbut-2- } \\
\text { enyl)-cyclohexene }\end{array}$ & 4.746 & 20.228 & 16 & 222.372 & 1 & 1 & 0 & 3 & 247.988 \\
\hline 19 & 3-o-methyl-d-glucose & -2.245 & 107.217 & 13 & 194.183 & 6 & 4 & 0 & 6 & 173.348 \\
\hline 20 & Vitamin E & 9.043 & 29.462 & 31 & 430 & 2 & 1 & 1 & 12 & 474.499 \\
\hline 21 & Octacosane & 10.051 & 0 & 28 & 394.772 & 0 & 0 & 1 & 25 & 482.604 \\
\hline 24 & Lupeol & 8.293 & 20.228 & 31 & 426.729 & 1 & 1 & 1 & 1 & 461.604 \\
\hline 25 & $\begin{array}{l}\text { Beta.-D-mannopyranoside, } \\
\text { methyl }\end{array}$ & -1.505 & 99.38 & 13 & 194.183 & 6 & 4 & 0 & 3 & 169.335 \\
\hline 26 & Dichloromethane & 1.511 & 0 & 3 & 84.933 & 0 & 0 & 0 & 0 & 56.508 \\
\hline 27 & HOP-22 (29)-EN-3.BETA.-OL & 8.29 & 20.23 & 31 & 426.73 & 1 & 1 & 1 & 1 & 461.60 \\
\hline 28 & Di-n-decylsulfone & 8.50 & 34.14 & 23 & 346.62 & 2 & 0 & 1 & 18 & 379.62 \\
\hline 29 & $\begin{array}{l}\text { 3,7,11,15tetramethyl2hexadecen- } \\
\text { 1-ol }\end{array}$ & 6.76 & 20.23 & 21 & 296.54 & 1 & 1 & 1 & 13 & 349.38 \\
\hline 30 & Paclitaxel & 4.945 & 221.307 & 62 & 853.918 & 15 & 4 & 2 & 14 & 756.598 \\
\hline
\end{tabular}

Table 3: Toxicity risks assessment phytocompounds predicted by OSIRIS property explorer

\begin{tabular}{|c|c|c|c|c|c|}
\hline $\begin{array}{l}\text { Serial } \\
\text { number }\end{array}$ & Compounds name & Mutagenic & Tumorigenic & Irritant & $\begin{array}{l}\text { Reproductive } \\
\text { effect }\end{array}$ \\
\hline 1 & 1-hexyl-2-nitrocyclohexane & No & No & No & No \\
\hline 2 & $\begin{array}{l}\text { 2,4,4-trimethyl-3-hydroxymethyl-5a-(3-methyl-but-2-enyl)- } \\
\text { cyclohexene }\end{array}$ & No & No & No & No \\
\hline 3 & 3,7,11,15-tetramethyl-2-hexadecen-1-ol & No & No & No & No \\
\hline 4 & $\begin{array}{l}\text { 2R-acetoxymethyl-1,3,3-trimethyl-4t-(3-methyl-2-buten-1- } \\
\text { yl)-1t-cyclohexanol }\end{array}$ & No & No & No & No \\
\hline 5 & Alpha.-linolenic acid, trimethylsilyl ester & No & No & Yes & No \\
\hline 6 & Dl-.alpha.-tocopherol & No & No & No & No \\
\hline 7 & 22,23-dibromostigmasterol acetate & Yes & Yes & Yes & No \\
\hline 8 & Tritetracontane & No & No & No & No \\
\hline 9 & n-hexadecanoic acid & No & Yes & Yes & No \\
\hline 10 & n-decanoic acid & Yes & No & Yes & No \\
\hline 11 & Urs-12-En-28-Oic Acid, 3-Hydroxy-, Methyl Ester, (3.Beta) & No & No & No & No \\
\hline 12 & 16-heptadecenal & Yes & No & Yes & Yes \\
\hline 13 & Benzeneethanamine & Yes & No & No & No \\
\hline 14 & (s)-(+)-1-cyclohexylethylamine & No & No & No & No \\
\hline 15 & Tetratetracontane & No & No & No & No \\
\hline 16 & Pentadecanal & Yes & No & Yes & Yes \\
\hline
\end{tabular}


Table 3: (Continued)

\begin{tabular}{|c|c|c|c|c|c|}
\hline $\begin{array}{l}\text { Serial } \\
\text { number }\end{array}$ & Compounds name & Mutagenic & Tumorigenic & Irritant & $\begin{array}{l}\text { Reproductive } \\
\text { effect }\end{array}$ \\
\hline 17 & Phytol & Yes & yes & Yes & Yes \\
\hline 18 & 7,8-epoxylanostan-11-ol, 3-acetoxy & No & No & Yes & No \\
\hline 19 & $\begin{array}{l}\text { 1,3,3-trimethyl-2-hydroxymethyl-3,3-dimethyl-4-(3- } \\
\text { methylbut-2-enyl)-cyclohexene }\end{array}$ & No & No & No & No \\
\hline 20 & 3-o-methyl-d-glucose & No & No & No & No \\
\hline 21 & Vitamin E & No & No & No & No \\
\hline 23 & 7-hexadecyne & No & No & No & No \\
\hline 24 & 13-tetradece-11-yn-1-ol & No & No & Yes & No \\
\hline 25 & Lupeol & No & No & No & No \\
\hline 26 & Beta-D-mannopyranoside, methyl & No & No & No & No \\
\hline 27 & Dichloromethane & Yes & Yes & Yes & Yes \\
\hline 28 & Di-n-decylsufone & No & No & No & No \\
\hline 29 & HOP-22 (29)-EN-3.BETA.-OL & No & No & No & No \\
\hline 30 & Paclitaxel & No & No & No & No \\
\hline
\end{tabular}

Table 4: Analysis of free binding energy of paclitaxel and phytocompounds with native and mutant (F270V) type $\beta$-tubulin protein

\begin{tabular}{|c|c|c|c|}
\hline $\begin{array}{l}\text { Serial } \\
\text { number }\end{array}$ & Compounds name & $\begin{array}{l}\text { Native binding } \\
\text { energy (kcal/mol) }\end{array}$ & $\begin{array}{l}\text { Mutant (F270V) binding } \\
\text { energy }(\mathrm{kcal} / \mathrm{mol})\end{array}$ \\
\hline 1 & 1-hexyl-2-nitrocyclohexane & 5.403 & 5.607 \\
\hline 2 & 2,4,4-trimethyl-3-hydroxymethyl-5a-(3-methyl-but-2-enyl)-cyclohexene & 6.399 & 5.947 \\
\hline 3 & 2R-acetoxymethyl-1,3,3-trimethyl-4t-(3-methyl-2-buten-1-yl)-1t-cyclohexanol & 6.630 & 6.822 \\
\hline 4 & Alpha.-linolenic acid, trimethylsilyl ester & - & - \\
\hline 5 & Dl-.alpha.-tocopherol & 6.633 & 5.948 \\
\hline 6 & 22,23-dibromostigmasterol acetate & 6.192 & 6.939 \\
\hline 8 & n-hexadecanoic acid & 5.279 & 5.339 \\
\hline 9 & n-decanoic acid & 4.806 & 4.726 \\
\hline 10 & Urs-12-En-28-Oic Acid, 3-Hydroxy-, Methyl Ester, (3.Beta.) & 8.036 & 9.427 \\
\hline 11 & 16-heptadecanal & 5.059 & 4.574 \\
\hline 12 & Benzeneethanamine & 4.988 & 5.276 \\
\hline 13 & $(\mathrm{~s})-(+)-1$-cyclohexylethylamine & 5.472 & 5.182 \\
\hline 14 & Tetratetracontane & 3.119 & 4.072 \\
\hline 15 & Pentadecanal & 4.746 & 4.624 \\
\hline 17 & 7,8-epoxylanostan-11-ol, 3-acetoxy & 7.643 & 8.715 \\
\hline 18 & $\begin{array}{l}\text { 1,3,3-trimethyl-2-hydroxymethyl-3,3-dimethyl-4-(3-methylbut-2-enyl)- } \\
\text { cyclohexene }\end{array}$ & 5.864 & 6.565 \\
\hline 19 & 3-o-methyl-d-glucose & 4.595 & 4.846 \\
\hline 20 & Vitamin E & 6.333 & 5.948 \\
\hline 21 & Octacosane & 3.952 & 3.128 \\
\hline 22 & 7-hexadecyne & 5.099 & 5.082 \\
\hline 23 & 13-tetradece-11-yn-1-ol & 4.873 & 4.498 \\
\hline 24 & Lupeol & 8.965 & 8.139 \\
\hline 25 & Beta.-D-mannopyranoside, methyl & 8.965 & 5.281 \\
\hline 26 & Dichloromethane & 2.302 & 2.514 \\
\hline 27 & HOP-22 (29)-EN-3.BETA.-OL & 9.221 & 9.445 \\
\hline 28 & Di-n-decylsulfone & 4.232 & 5.173 \\
\hline 29 & $3,7,11,15$ tetramethyl2hexadecen-1-ol & 6.229 & 6.271 \\
\hline 30 & Paclitaxel & 8.759 & 7.511 \\
\hline
\end{tabular}

-: Indicates the docking energy is not available

pace in identifying potent natural products, by employing computeraided program PASS for drug discovery.

\section{Pass prediction analysis for anticancer activity}

The biological activity spectrum of the compound HOP-22(29)-EN-3. BETA.-OL was obtained by online PASS version. The biological activity spectra (anticancer) evaluated was found in the criteria. PASS predicted probable activity (Pa) of the compound HOP-22(29)-EN-3.BETA.-OL for antineoplastic activity is 0.935 and antineoplastic (ovarian cancer) activity is 0.736 . Therefore, it is likely to be the potential lead molecule for the inhibition of $\beta$-tubulin. Of note, compound HOP-22(29)-EN-3. BETA.-OL shows antineoplastic activity for ovarian cancer with the Pa>0.7. Hence, HOP-22(29)-EN-3.BETA.-OL is proven to be a potent anticancer agent. In future, it may offer an alternative source of drug for the treatment of ovarian cancer.

\section{CONCLUSIONS}

Here, we report the identification of novel molecule, HOP-22(29)-EN-3. BETA.-OL, which binds effectively with both the native and mutant $\beta$-tubulin structures. The results of our study signify that bioavailability of HOP-22(29)-EN-3.BETA.-OL is significantly higher than paclitaxel. In addition, the compound showed no cytotoxicity in the computational analysis. Moreover, the binding energy between HOP-22(29)-EN-3. BETA.-OL and $\beta$-tubulin was found to be significantly higher than energies between paclitaxel and other plant bioactives with $\beta$-tubulin. 


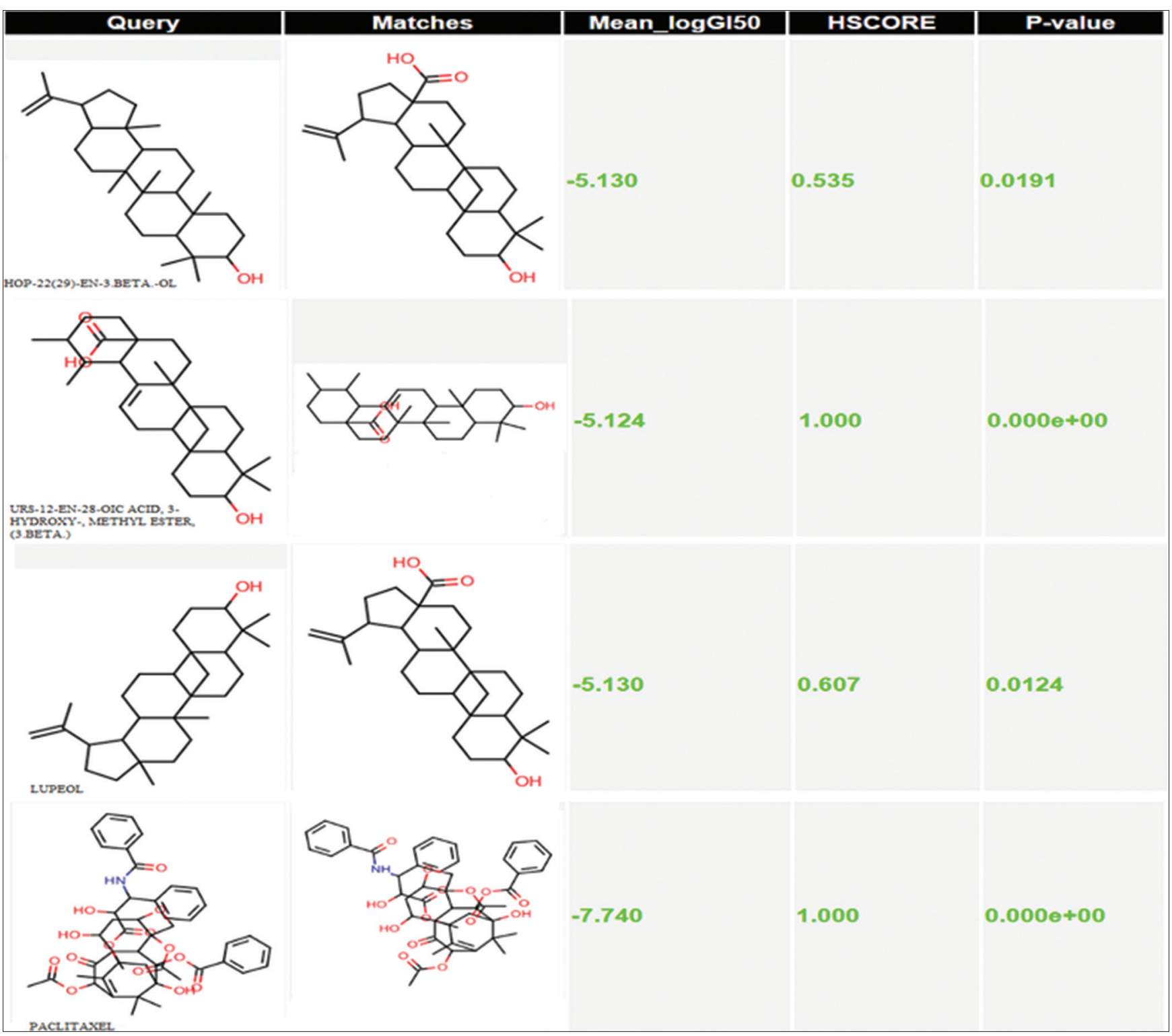

Fig. 1: Anticancer activity analysis of the compounds using CDRUG

This docking result also suggests that HOP-22(29)-EN-3.BETA.-OL interacts well with the residues of the binding site of $\beta$-tubulin even in the mutant form. Finally, the data obtained from the CDRUG and PASS confirmed that HOP-22(29)-EN-3.BETA.-OL is found to have anticancer activity. We believe that the present study will be of great help in designing the drugs for cancer treatment. This is the first observation of HOP-22(29)-EN-3.BETA.-OL inhibitory action toward the target protein $\beta$-tubulin and further needs to be justified by the experimental support.

\section{ACKNOWLEDGMENT}

The authors of the manuscript would like to thank the management of VIT University for providing the facility and support to carry out this research work.

\section{REFERENCES}

1. Mollinedo F, Gajate C. Microtubules, microtubule-interfering agents and apoptosis. Apoptosis 2003;8(5):413-50.

2. Zhou J, Giannakakou P. Targeting microtubules for cancer chemotherapy. Curr Med Chem Anticancer Agents 2005;5(1):65-71.

3. Jordan A, Hadfield JA, Lawrence NJ, McGown AT. Tubulin as a target for anticancer drugs: Agents which interact with the mitotic spindle. Med Res Rev 1998;18(4):259-96.
4. Dumontet C, Sikic BI. Mechanisms of action of and resistance to antitubulin agents: Microtubule dynamics, drug transport, and cell death. J Clin Oncol 1999;17(3):1061-70.

5. Newman DJ, Cragg GM, Snader KM. Natural products as sources of new drugs over the period 1981-2002. J Nat Prod 2003;66(7):1022-37.

6. Cragg GM, Newman DJ. Plants as a source of anti-cancer agents. J Ethnopharmacol 2005;100(1-2):72-9.

7. Anusha K, Govindappa M, Channabasava R, Chandrappa CP, Ramachandra YL, Prasad SK. Phytochemical analysis of Cassia fistula and its in vitro antimicrobial, antioxidant and anti-inflammatory activities. AMPR 2015;3(1):8-17.

8. Anusha K, Govindappa M, Ramachandra YL, Prasad SK. GC-MS analysis of methanol extract of cassia fistula and its in vitro anticancer activity on human prostate cancer cell line. IAJPS 2015;5(2):937-44.

9. Theeshan B, Vidushi SN, Okezie IA. Phytochemical constituents of cassia fistula. Afr J Biotechnol 2005;4(13):1530-40.

10. Kalaiselvan A, Gokulakrishnan K, Anand T. Gas chromatography-Mass spectrum analysis of bioactive components of the ethanol extract of Andrographis paniculata. J Pharm Biomed Sci 2012;20(20):1-3.

11. Ambritha B, Rekha R, Shanthia S, Monisha $T$, Lavanya $R$, Ramanathan $\mathrm{K}$, et al. Investigation of Phytocompounds and Computational Approach for the Evaluation of Therapeutic Properties of Ethanolic Leaf Extract of Callistemon citrinus. Int J Pharm Sci Rev Res 2016;37(1):110-6.

12. Feng QL, Wu J, Chen GQ, Cui FZ, Kim TN, Kim JO. A mechanistic 
study of the antibacterial effect of silver ions on Escherichia coli and Staphylococcus aureus. J Biomed Mater Res 2000;52(4):662-8.

13. Ravichandran V, Tiah ZX, Subashini G, Terence FW, Eddy FC, Nelson J, et al. Biosynthesis of silver nanoparticles using mangosteen leaf extract and evaluation of their antimicrobial activities. J Saudi Chem Soc 2011;15:113-20.

14. Sermakkani M, Thangapandian V. GC-MS Analysis of cassia italic leaf methanol extract. Asian J Pharm Clin Res 2012;5(2):90-4.

15. Devi KV, Shanmugasundaram R, Mohan VR. GC-MS Analysis of ethanol extract of Entadapursaetha DC seed. Biosci Discov 2012;3(1):30-3.

16. Elavarasi S, Saravanan K, Renuka C. A systematic review on medicinal plants used to treat diabetes mellitus. IJPCBS 2013;3(3):983-92.

17. Subashri B, Justin Koil Pillai Y. A comparative study of antioxidant activity of Baccopa monnieri (L.) pennell using various solvent extracts and its GC-MS Analysis. Int J Pharm Pharm Sci 2014;6(2):494-8.

18. Xu S, Chi S, Jin Y, Shi Q, Ge M, Wang S, et al. Molecular dynamics simulation and density functional theory studies on the active pocket for the binding of paclitaxel to tubulin. J Mol Model 2012;18(1):377-91.

19. Guex N, Peitsch MC. SWISS-MODEL and the Swiss-PdbViewer: An environment for comparative protein modeling. Electrophoresis 1997;18(15):2714-23.

20. Feldman HJ, Snyder KA, Ticoll A, Pintilie G, Hogue CW. A complete small molecule dataset from the protein data bank. FEBS Lett 2006;580(6):1649-53.

21. Gasteiger J, Rudolph C, Sadowski J. Automatic generation of 3D-atomic coordinates for organic molecules. Tetrahedron Comput Methodol 1990;3:537-47.

22. Ertl P, Rohde B, Selzer P. Fast calculation of molecular polar surface area as a sum of fragment-based contributions and its application to the prediction of drug transport properties. J Med Chem 2000;43(20):3714-7.

23. Lipinski CA, Lombardo F, Dominy BW, Feeney PJ. Experimental and computational approaches to estimate solubility and permeability in drug discovery and development settings. Adv Drug Deliv Rev 1997;23:3-25

24. Muegge I. Selection criteria for drug-like compounds. Med Res Rev 2003;23(3):302-21.

25. Buntrock RE. ChemOffice Ultra 7.0. J Chem Inf Comput Sci 2002;42(6):1505-6.

26. Sander T. OSIRIS Property Explorer. Allschwil: Actelion Pharmaceuticals Ltd.; 2001

27. Trott O, Olson AJ. AutoDock Vina: Improving the speed and accuracy of docking with a new scoring function, efficient optimization, and multithreading. J Comput Chem 2010;31(2):455-61.

28. Krieger E, Vriend G. Models@Home: Distributed computing in bioinformatics using a screensaver based approach. Bioinformatics 2002;18(2):315-8.

29. Li GH, Huang JF. CDRUG: A web server for predicting anticancer activity of chemical compounds. Bioinformatics 2012;28(24):3334-5.

30. Li GH, Huang JF. Inferring therapeutic targets from heterogeneous data: HKDC1 is a novel potential therapeutic target for cancer. Bioinformatics 2014;30(6):748-52.

31. Khurana N, Ishar MP, Gajbhiye A, Goel RK. PASS assisted prediction and pharmacological evaluation of novel nicotinic analogs for nootropic activity in mice. Eur J Pharmacol 2011;662(1-3):22-30.

32. Goel RK, Singh D, Lagunin A, Poroikov V. Pass-assisted exploration of new therapeutic potential of natural products. Med Chem Res 2011;20(9):1509-14. 